\title{
Hypertension impairs myocardial blood perfusion reserve in subjects without regional myocardial ischemia
}

\begin{abstract}
Hiroshi Nakajima ${ }^{1}$, Katsuya Onishi ${ }^{1}$, Tairo Kurita ${ }^{1}$, Masaki Ishida ${ }^{2}$, Motonori Nagata ${ }^{2}$, Kakuya Kitagawa ${ }^{2}$, Kaoru Dohi ${ }^{1}$, Mashio Nakamura ${ }^{1}$, Hajime Sakuma ${ }^{2}$ and Masaaki Ito ${ }^{1}$

Quantitative analysis of myocardial perfusion MRI can provide noninvasive assessments of myocardial perfusion reserve (MPR), which is associated with endothelial function. Endothelial function is influenced by various factors, including hypertension, diabetes, dyslipidemia, renal dysfunction and anemia. The purpose of this study was to evaluate which risk factor is the strongest effector of MPR in subjects without regional myocardial ischemia. We studied 110 patients (66 years \pm 10 , male $68 \%$, hypertension $76 \%$, diabetes mellitus (DM) $40 \%$ and dyslipidemia $65 \%$ ) without regional myocardial ischemia. Adenosine triphosphate (ATP) stress and rest first-pass perfusion magnetic resonance (MR) images were acquired with a 1.5-T MR system, and MPR was calculated as the ratio of stress to rest myocardial blood flow (MBF). Average rest MBF in 110 patients was $1.07 \pm 0.62 \mathrm{ml} \mathrm{min}^{-1} \mathrm{~g}^{-1}$, whereas stress MBF was $3.15 \pm 1.93 \mathrm{ml} \mathrm{min}^{-1} \mathrm{~g}^{-1}$ and the MPR was $3.33 \pm 1.82$. Rest MBF correlated significantly with hematocrit, whereas stress MBF showed a strong correlation with estimated glomerular filtration rate (e-GFR). MPR was associated with hypertension, age, e-GFR, hematocrit and left ventricular mass index (LVMI). In multiple regression analysis, hypertension $(P=0.003, \beta=-0.274)$ showed the strongest correlation with MPR among other risk factors,

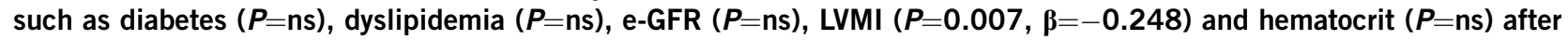
adjusting age and gender. Hypertension is the most important effector of MPR in subjects without myocardial ischemia. Hypertension Research (2010) 33, 1144-1149; doi:10.1038/hr.2010.140; published online 5 August 2010
\end{abstract}

Keywords: coronary risk factor; MRI; myocardial blood flow

\section{INTRODUCTION}

Myocardial perfusion reserve (MPR) is affected by endothelial dysfunction and micro-circulation status. It is not surprising that MPR is often abnormal in individuals without evidence of coronary heart disease but with risk factors, including hypertension, diabetes and dyslipidemia. ${ }^{1-4}$ The search for impaired MPR may add valuable information to the cardiovascular risk assessment of hypertensive patients. Which risk factor is the most important contributor to impaired MPR is not yet clear. In the Multi-Ethnic Study of Atherosclerosis (MESA) trial, it was reported that reduced MPR was independently associated with high blood pressure and high lowdensity lipoprotein cholesterol, but was not associated with cigarette smoking, obesity, physical activity or diabetes. ${ }^{5}$ Although substantial evidence supported the contention that coronary risk factors are associated with reduced MPR, the association between MPR and various factors relating to endothelial dysfunction, including aging, anemia, renal dysfunction and left ventricular (LV) mass index (LVMI), have not been evaluated. To evaluate the relationship between MPR and risk factors for endothelial dysfunction, MPR was assessed by using stress first-pass myocardial perfusion MRI, which has been shown as a promising noninvasive method to evaluate myocardial blood flow (MBF) without ionizing radiation. ${ }^{6}$ Both relative and absolute blood flow can be reproducibility quantified using a firstpass magnetic resonance perfusion MRI approach. ${ }^{7-9}$ The high spatial resolution of MRI allows quantification of regional transmural flow gradients. ${ }^{10}$ MPR can be calculated from the ratio of adenosine triphosphate (ATP) during stress and rest MBF, which is determined using myocardial and blood signal intensity time curves. ${ }^{11-15}$

Accordingly the purpose of this study was to evaluate which risk factor is the strongest effector of MPR in subjects without regional myocardial ischemia.

\section{METHODS}

Study subjects

Study subjects were recruited from 708 participants who underwent contrast enhanced myocardial perfusion MRI with stress in our hospital. Following were the inclusion criteria: (1) normal LV function without LV asynergy on cine MRI; (2) no regional myocardial ischemia on stress myocardial perfusion MRI;

${ }^{1}$ Department of Cardiology, Mie University Graduate School of Medicine, Tsu, Japan and ${ }^{2}$ Department of Diagnostic Radiology, Mie University Graduate School of Medicine, Tsu, Japan

Correspondence: Dr K Onishi, Department of Cardiology, Mie University Graduate School of Medicine, 2-174 Edobashi, Tsu 514-8507, Japan.

E-mail: katsu@clin.medic.mie-u.ac.jp

Received 29 December 2009; revised 4 June 2010; accepted 8 June 2010; published online 5 August 2010 
and (3) no myocardial infarction on late gadolinium-enhanced MRI. Patients with a history of cardiomyopathy, amyloidosis, previous coronary bypass grafting, irregular heart rhythm, such as atrial fibrillation, chronic renal failure (estimated glomerular filtration rate (e-GFR) $<30 \mathrm{ml} \mathrm{min}^{-1} 1.73 \mathrm{~m}^{-2}$ ), including hemodialysis and valvular heart disease, were excluded from this study. Patients with pacemakers, intracranial clips or a contraindication to receiving ATP were also excluded from this study. As a result, 110 subjects $(65.7 \pm 10.2$ years of age, $68 \%$ male) were recruited to this study (Figure 1 ). In the recruited subjects, 84 patients were asymptomatic patients and 26 patients had chest pain. Coronary angiography and/or thallium single-photo emission-computed tomography were performed in these 26 patients, and no evidence of ischemic heart disease was found in 20 of 26 patients with chest pain. The study protocol was approved by the Institutional Ethics Committee and written informed consent was obtained from all subjects.

\section{MRI acquisition}

Participants were asked to abstain from caffeine intake for $12 \mathrm{~h}$ before their cardiac MR exam. First-pass contrast-enhanced myocardial perfusion MR images were obtained during ATP stress and in the resting state by using a 1.5-T clinical MR scanner (Achieva 1.5 T, Philips Medical Systems, Best, the Netherlands) and a 5-channel cardiac receiver coil. Initial scout MR images were obtained to determine the position of the heart and diaphragm. Then, steady-state cine MRIs on the short axis imaging planes of the LV were acquired. Myocardial perfusion MR images were acquired with steady-state perfusion MR sequence with non-slice-selective saturation recovery preparation (four short-axis imaging slices, two images per heart beat, $3.0 \mathrm{~ms}$ repetition time, $1.2 \mathrm{~ms}$ echo time, 45 degree flip angle and $150 \mathrm{~ms}$ between the saturation preparation pulse and the center of k-space acquisition, $36 \times 32 \mathrm{~cm}$ field of view, $128 \times 128$ acquisition matrices and $8 \mathrm{~mm}$ section thickness). For both stress and rest perfusion MRIs, gadolinium contrast medium (gadopentetate dimeglumine, Magnevist, Schering, Berlin, Germany) was injected into the right antecubital vein at a dose of $0.05 \mathrm{mmol} \mathrm{kg}^{-1}$ with a power injector at a flow rate of $4 \mathrm{ml} \mathrm{s}^{-1}$, followed by a 20-ml saline flush. Dynamic MR images were acquired for $1 \mathrm{~min}$. The patients were instructed to begin holding their breath at the start of the image acquisition and to maintain the breath hold as long as possible. To correct the nonlinear relationship between the blood concentration of MR contrast medium and MR blood signal intensity during first-pass, a dual bolus method was used by injecting a bolus of diluted contrast medium $\left(0.005 \mathrm{mmol} \mathrm{kg}^{-1}\right)$ before perfusion MRI that does not exhibit saturation of the blood signal. ${ }^{16}$

Pharmacological stress was performed by injecting ATP $\left(160 \mu \mathrm{g} \mathrm{kg}^{-1} \mathrm{~min}^{-1}\right)$ in the left antecubital vein for $4 \mathrm{~min}$. Symptoms, blood pressure, heart rate and ECG were monitored while the patients were in the magnet, and any serious adverse reaction caused by the pharmacologic stress was recorded throughout the MRI examination. At 3 min after starting ATP administration, the acquisition of stress myocardial perfusion MR images were initiated and ATP was continuously injected during the acquisition of the stress perfusion MRI. Rest myocardial perfusion MRIs were acquired at least $10 \mathrm{~min}$ after finishing the stress myocardial perfusion MRI.

\section{Assessment of MBF and MPR}

Rest-stress, first-pass myocardial perfusion MR images were analyzed using an image analysis workstation (Virtual Place, Aze, Tokyo, Japan). Epicardial and endocardial contours of the LV myocardium were manually determined to obtain myocardial time-intensity curves, and the region of interest was placed in the LV chamber to generate a blood time-intensity curve. The LV myocardium was divided into 16 segments, consisting of 6 basal segments, 6 mid-ventricular segments and 4 apical segments on the basis of the AHA 17segment model, excluding the apical segment. Signal saturation of the LV blood signal was corrected using a dual bolus method. Patlak plot analysis was performed using blood the time-intensity curve as an input function and the regional myocardial time-intensity curve as an output function. ${ }^{8}$ The range of the least square fitting for Patlak plot analysis was automatically optimized using an algorithm that maximizes the correlation coefficient of the least square fitting. After calculating perfusion parameter K1 in 16 myocardial segments, MBF was calculated as K1 divided by the extraction fraction of Gd-DTPA, using the extraction fraction values in the previous studies. MPR was determined as stress MBF divided by rest MBF. Several recent studies including our studies have found a good correlation between adenosine stress perfusion MR results and the invasively measured coronary fractional flow reserve. ${ }^{6,17}$

\section{Definition and measurement of risk factors}

Hypertension was defined as resting seated systolic blood pressure $\geqslant 140 \mathrm{~mm} \mathrm{Hg}$, diastolic blood pressure $\geqslant 90 \mathrm{~mm} \mathrm{Hg}$ using an oscillometric sphygmomanometer in the hospital and/or self-reported history of hypertension

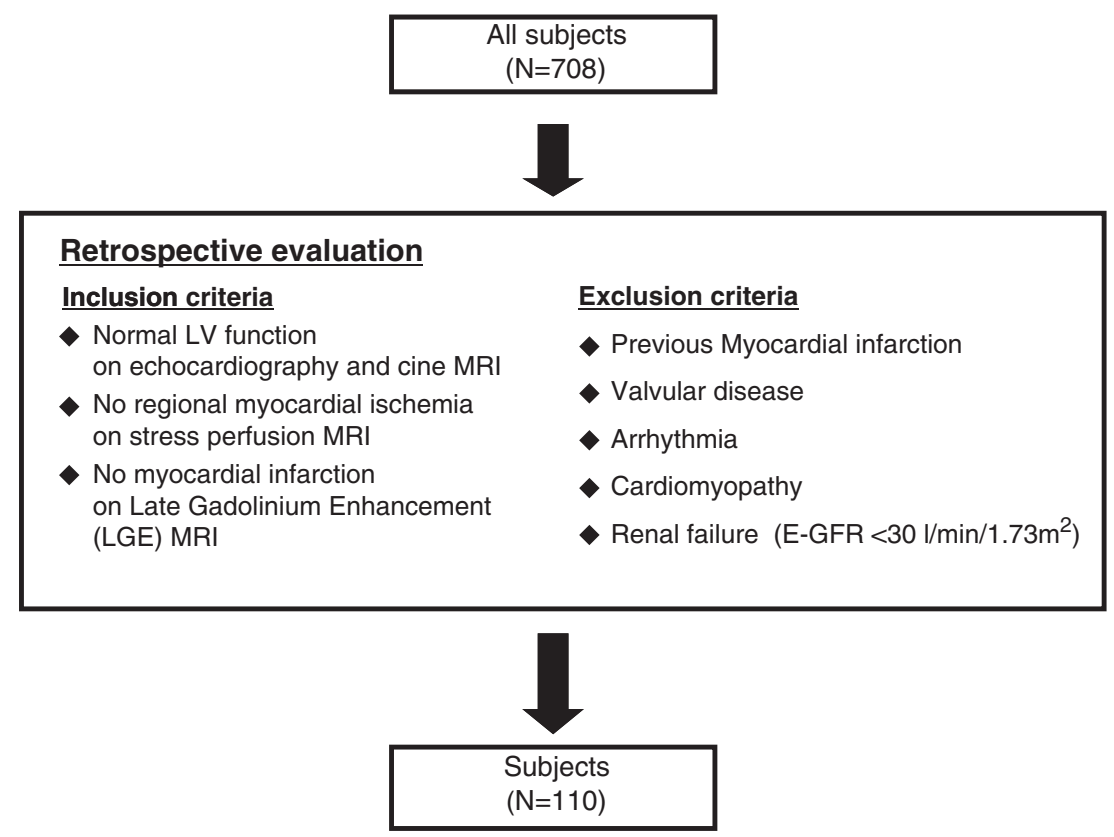

Figure 1 Flow diagram of patients for enrollment and reasons for exclusion. For study enrollment, the subjects were selected from 708 subjects who underwent echocardiography and cardiac MRI. We selected 110 subjects who satisfied the inclusion and exclusion criteria. 
on at least two different occasions and/or taking anti-hypertensive medications. Blood samples were obtained from participants after $12 \mathrm{~h}$ of fasting and analyzed at a central laboratory in our hospital for glucose, total cholesterol, low-density lipoprotein (LDL) cholesterol and high-density lipoprotein (HDL) cholesterol. Dyslipidemia was defined as total cholesterol $\geqslant 220 \mathrm{mg}$ per $100 \mathrm{ml}$ and/or triglyceride $\geqslant 150 \mathrm{mg}$ per $100 \mathrm{ml}$ and/or LDL cholesterol $\geqslant 140 \mathrm{mg}$ per $100 \mathrm{ml}$ and/or HDL cholesterol $\leqslant 40 \mathrm{mg}$ per $100 \mathrm{ml}$. DM was defined as fasting glucose $\geqslant 126 \mathrm{mg}$ per $100 \mathrm{ml}$, and/or a self reported history of diabetes, and/or taking diabetes medications. Smoking was defined as lifetime consumption for cigarettes.

\section{Statistical analysis}

All data were expressed as the mean \pm the standard deviation. Analysis was performed using SPSS version 11.5 (SPSS Inc, Chicago, IL, USA).

The perfusion and hemodynamic measurements were compared across categories of risk factors using a Student's $t$-test. Spearman correlation coefficients were calculated between continuous risk factors and perfusion measurements. Stepwise multiple linear regression analysis was performed to estimate the difference in MBF and MPR predicted by a given difference in risk factor. A value of $P<0.05$ was considered statistically significant.

\section{RESULTS}

\section{Patient background and characteristics}

Patients' backgrounds are summarized in Table 1. Mean hemoglobin levels were $13.5 \pm 1.6 \mathrm{mg}$ per $100 \mathrm{ml}$ (range: $8.9-17.1$ ), mean hematocrit levels were $41.1 \pm 4.4 \%$ (range: $28.3-41.1$ ) and mean e-GFR were $62.2 \pm 15.61 \mathrm{~min}^{-1}$ per $1.73 \mathrm{~m}^{2}$ (range: $31.9-121.9$ ).

\section{Example of myocardial perfusion maps}

All patients tolerated the cardiac MR procedures and there were no complications. Figure 2 illustrates a typical example of MBF maps in

Table 1 Clinical characteristics data of patients

\begin{tabular}{|c|c|}
\hline $\mathrm{n}=$ & 110 \\
\hline Age, yrs & $66 \pm 10$ \\
\hline Gender (male), n (\%) & $75(68 \%)$ \\
\hline Systolic blood pressure (SBP), $\mathrm{mm} \mathrm{Hg}$ & $135 \pm 22$ \\
\hline Diastolic blood pressure (DBP), $\mathrm{mm} \mathrm{Hg}$ & $76 \pm 13$ \\
\hline Heart rate $(\mathrm{HR}), \mathrm{bpm}$ & $67 \pm 11$ \\
\hline Left ventricular ejection fraction (EF), \% & $62.7 \pm 7.7$ \\
\hline Left ventricular mass index (LVMI), $\mathrm{g} \mathrm{m}^{-2}$ & $61.5 \pm 19.0$ \\
\hline Hemoglobin $(\mathrm{Hb})$, mg per $100 \mathrm{ml}^{-1}$ & $13.5 \pm 1.6$ \\
\hline Hematocrit (Ht), \% & $41.1 \pm 4.4$ \\
\hline Body Mass Index (BMI), $\mathrm{kg} \mathrm{m}^{-2}$ & $24.2 \pm 3.5$ \\
\hline $\begin{array}{l}\text { Estimated glomerular filtration ratio } \\
\text { (e-GFR: MDRD), I } \mathrm{min}^{-1} \text { per } 1.73 \mathrm{~m}^{2}\end{array}$ & $62.2 \pm 15.6$ \\
\hline \multicolumn{2}{|l|}{ Coronary risk factor } \\
\hline Hypertension, $n(\%)$ & $84(76 \%)$ \\
\hline Diabetes, $n(\%)$ & $44(40 \%)$ \\
\hline Dyslipidemia, $n(\%)$ & $72(65 \%)$ \\
\hline Smoking, $n(\%)$ & $35(32 \%)$ \\
\hline Obesity, $n(\%)$ & $41(37 \%)$ \\
\hline Family history, $n(\%)$ & $16(15 \%)$ \\
\hline \multicolumn{2}{|l|}{ Medication } \\
\hline Beta blocker, $n(\%)$ & $24(22 \%)$ \\
\hline ACE-I/ARB, $n(\%)$ & $48(44 \%)$ \\
\hline Diuretics, $n(\%)$ & $9(8 \%)$ \\
\hline HMG-CoA inhibitor, $n(\%)$ & $26(24 \%)$ \\
\hline
\end{tabular}

Abbreviations: ACE-I, angiotensin converting enzyme inhibitor; ARB, angiotensin receptor blocker; HMG-COA, hydroxymethylglutaryl-CoA reductase inhibitor; MDRD, modification of diet in renal disease. the resting state and during stress, in a subject without risk factor and in another subject with hypertension, LVH and low e-GFR. In the resting state, MBF was approximately $1 \mathrm{ml} \mathrm{min}^{-1} \mathrm{~g}^{-1}$ of the myocardial tissue in both cases. By contrast, during ATP stress, MBF increased to $3 \mathrm{ml} \mathrm{min}^{-1} \mathrm{~g}^{-1}$ in a subject without risk factors, whereas the augmentation of MBF by stress was impaired in this case with hypertension, LVH and low e-GFR.

\section{The mean value of rest and stress MBF}

Average global rest MBF was $1.07 \pm 0.62 \mathrm{ml} \mathrm{min}^{-1} \mathrm{~g}^{-1}$ (range: $0.34-$ $\left.2.72 \mathrm{ml} \mathrm{min}^{-1} \mathrm{~g}^{-1}\right)$. ATP stress raised MBF to $3.15 \pm 1.93 \mathrm{ml} \mathrm{min}^{-1} \mathrm{~g}^{-1}$ (range: $0.33-12.10$ ), resulting in an average MPR of $3.33 \pm 1.82$ (range 0.34-11.8).

Univariate analysis investigating the relation between MBF and multiple risk factors is summarized on Table 2 . Both the rest (0.96 vs. $1.31 ; P=0.015)$ and stress $\mathrm{MBF}(2.74$ vs. $4.03 ; P=0.004)$ were significantly lower in males than in females. However, there was no significant difference in MPR between males and in females (3.19 vs. $3.63 ; P=0.239)$. As for the hypertension, there was no difference in resting MBF between the two groups ( 1.09 vs. $0.99 ; P=0.436$ ), whereas the MPR was significantly lower in the hypertension group compared with that in non-hypertension group ( 3.01 vs. $4.35 ; P=0.01$ ). All other risk factors, including diabetes, smoking, dyslipidemia, family history and obesity, showed no significant differences between the two groups.

Spearman correlation analysis between myocardial perfusion measurements and risk factors are shown in Table 3. Although the rest MBF and stress MBF did not exhibit significant association with age, MPR shows a weak but significant correlation with age. Hematocrit correlated negatively with rest MBF and e-GFR correlated positively with stress MBF. Finally, LVMI showed a significant association with MPR.

In addition to the univariate analysis, we performed multivariate adjusted linear regression analysis. Age was not significantly associated with MBF or MPR. Gender correlated with rest MBF and ATP stress MBF, but not with MPR. LVMI also showed a negative correlation with $\operatorname{MPR}(P=0.007, \beta=-0.248)$. Among these risk factors, hypertension showed the most significant negative correlation with ATP stress $\operatorname{MBF}(P=0.013, \beta=-0.226$, ) and MPR $(P=0.003, \beta=-0.274)$. The other risk factors showed no significant correlation with the perfusion parameters by multivariate analysis (Table 4 ).

\section{DISCUSSION}

In the present study, we demonstrated that hypertension is most strongly associated with MPR among risk factors.

The presence of an abnormal MPR despite angiographically normal coronary arteries has been demonstrated. ${ }^{18,19}$ Possible mechanisms included a structural remodeling of the coronary microvasculature and the accumulation of fibrillar collagen in the myocardium that might increase minimal resistance, an increase in the extravascular component of coronary resistance due to an augmentation of myocardial tissue pressure during diastole, and a functional increase in the tonus of the coronary resistance vessels with reduced endotheliumdependent relaxation in response to adenosine diphosphate. ${ }^{19,20}$ Therefore, detecting the impairment of global MPR would provide valuable information for cardiovascular risk assessment. Lu Wang et al. demonstrated that reduced MPR was independently associated with hypertension, higher diastolic blood pressure and higher total cholesterol and LDL cholesterol after adjusting for age, gender and race. They also demonstrated the cross sectional relationship between myocardial perfusion and age, gender, race and physical activity, in addition to coronary disease risk factors. ${ }^{21}$ However, the MBF and 
a

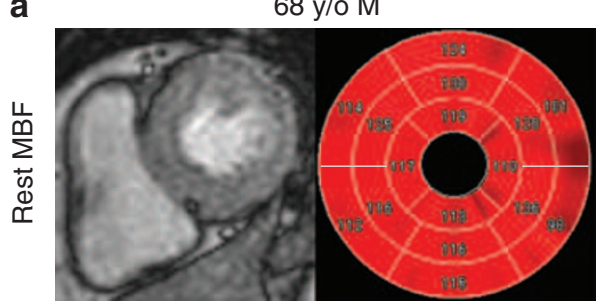

$1.1 \mathrm{ml} / \mathrm{min} / \mathrm{g}$

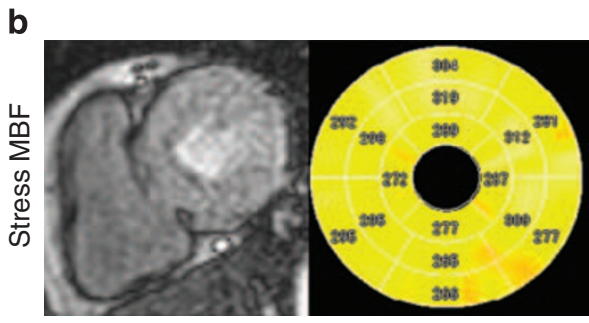

$2.9 \mathrm{ml} / \mathrm{min} / \mathrm{g}$

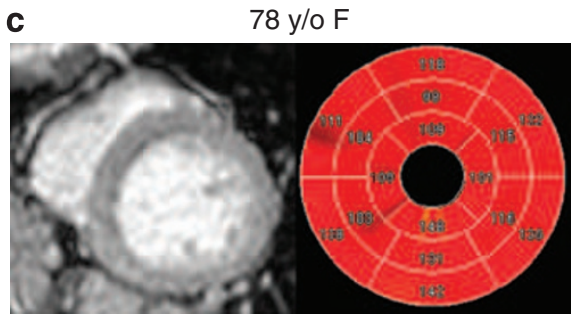

$1.2 \mathrm{ml} / \mathrm{min} / \mathrm{g}$

d

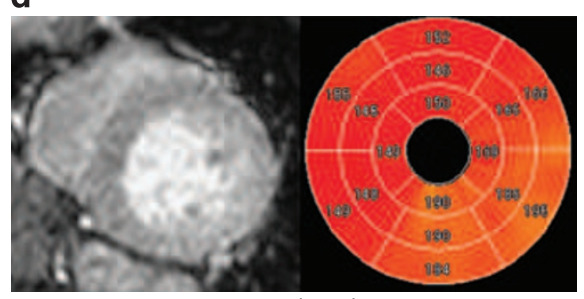

$1.6 \mathrm{ml} / \mathrm{min} / \mathrm{g}$

Figure 2 Examples of MBF images and maps in the resting state and during stress; the top row shows rest MBF images and the bottom row shows stress MBF images. (a) Rest MBF in a subject without risk factors was approximately $1.1 \mathrm{ml} \mathrm{min}^{-1} \mathrm{~g}^{-1}$. (b) And stress $\mathrm{MBF}$ increased to $2.9 \mathrm{ml} \mathrm{min}-1 \mathrm{~g}^{-1}$. (c) Rest MBF in a patient with hypertension, low e-GFR was $1.2 \mathrm{ml} \mathrm{min}^{-1} \mathrm{~g}^{-1}$. (d) Augmentation of MBF by stress was impaired $\left(1.6 \mathrm{ml} \mathrm{min}^{-1} \mathrm{~g}^{-1}\right)$ in this case.

Table 2 Unadjusted mean perfusion measurements and hemodynamic parameters across categories of participant characteristics

\begin{tabular}{|c|c|c|c|c|}
\hline Risk factors & $\mathrm{n}=$ & Rest MBF & Stress MBF & $M P R$ \\
\hline \multicolumn{5}{|l|}{ Gender } \\
\hline Male & 75 & 0.95790 & 2.73885 & 3.18529 \\
\hline Female & 35 & 1.30758 & 4.02793 & 3.62555 \\
\hline$P=$ & & 0.015 & 0.004 & 0.239 \\
\hline \multicolumn{5}{|l|}{ Hypertension } \\
\hline Yes & 84 & 1.09491 & 2.91165 & 3.00747 \\
\hline No & 26 & 0.98596 & 3.91588 & 4.35246 \\
\hline$P=$ & & 0.436 & 0.077 & 0.010 \\
\hline \multicolumn{5}{|l|}{ Diabetes } \\
\hline Yes & 44 & 1.06969 & 3.08214 & 3.28279 \\
\hline No & 66 & 1.06881 & 3.19360 & 3.35377 \\
\hline$P=$ & & 0.994 & 0.769 & 0.842 \\
\hline \multicolumn{5}{|l|}{ Smoking } \\
\hline Yes & 35 & 1.00326 & 3.19132 & 3.63489 \\
\hline No & 75 & 1.09992 & 3.12927 & 3.18093 \\
\hline$P=$ & & 0.448 & 0.876 & 0.224 \\
\hline \multicolumn{5}{|l|}{ Dyslipidemia } \\
\hline Yes & 72 & 1.12460 & 3.23101 & 3.30270 \\
\hline No & 38 & 0.96412 & 2.99365 & 3.36834 \\
\hline$P=$ & & 0.197 & 0.543 & 0.858 \\
\hline
\end{tabular}

Abbreviations: MBF, myocardial blood flow; MPR, myocardial perfusion reserve.

MPR were affected by not only these factors but also by anemia, LV wall thickness and renal dysfunction, which are related to endothelial dysfunction. ${ }^{22-24}$ Therefore, in the present study, we evaluated the relationship of MPR with anemia, LVMI and e-GFR, in addition to the traditional coronary risk factors that may affect endothelial function. In the current study, the stress MBF and MPR correlated more
Table 3 Spearman correlation analysis between myocardial perfusion measurements and risk factors

\begin{tabular}{|c|c|c|c|c|c|c|}
\hline \multirow[b]{2}{*}{ Risk factors } & \multicolumn{2}{|c|}{ Rest MBF } & \multicolumn{2}{|c|}{ Stress MBF } & \multicolumn{2}{|c|}{$M P R$} \\
\hline & $r$ & $\mathrm{P}$ & $r$ & $P$ & $r$ & $P$ \\
\hline Age & 0.11 & 0.241 & -0.07 & 0.478 & -0.23 & 0.011 \\
\hline Hematocrit & -0.32 & $<0.001$ & -0.05 & 0.555 & 0.25 & 0.006 \\
\hline e-GFR & -0.15 & 0.869 & 0.19 & 0.042 & 0.20 & 0.030 \\
\hline LVMI & 0.15 & 0.103 & -0.17 & 0.081 & -0.34 & $<0.001$ \\
\hline SBP & 0.100 & 0.298 & -0.122 & 0.203 & -0.241 & 0.011 \\
\hline DBP & -0.097 & 0.312 & -0.091 & 0.343 & 0.036 & 0.707 \\
\hline
\end{tabular}

Table 4 Results for stepwise multiple adjusted linear regression models of myocardial blood flow and myocardial perfusion measurements with risk factors

\begin{tabular}{|c|c|c|c|c|c|c|}
\hline \multirow[b]{2}{*}{ Risk factors } & \multicolumn{2}{|c|}{ Rest MBF } & \multicolumn{2}{|c|}{ ATP stress MBF } & \multicolumn{2}{|c|}{$M P R$} \\
\hline & $\beta$ & $P=$ & $\beta$ & $P=$ & $\beta$ & $P=$ \\
\hline Gender (male) & -0.200 & 0.035 & -0.315 & 0.001 & -0.088 & NS \\
\hline Age & 0.087 & NS & -0.018 & NS & -0.148 & NS \\
\hline e-GFR & 0.034 & NS & 0.113 & NS & 0.057 & NS \\
\hline Hypertension & 0.036 & NS & -0.226 & 0.013 & -0.274 & 0.003 \\
\hline Diabetes & 0.052 & NS & 0.008 & NS & -0.001 & NS \\
\hline Dyslipidemia & 0.132 & NS & 0.014 & NS & -0.028 & NS \\
\hline Smoking & -0.003 & NS & 0.033 & NS & 0.116 & NS \\
\hline Obesity & -0.164 & NS & -0.057 & NS & 0.099 & NS \\
\hline LVMI & 0.111 & NS & -0.122 & NS & -0.248 & 0.007 \\
\hline Hematocrit & -0.245 & 0.010 & -0.088 & NS & 0.084 & NS \\
\hline
\end{tabular}

Abbreviations: ATP, adenosine triphosphate; e-GFR, estimated glomerular filtration rate; LVMI, left ventricular mass index; MBF, myocardial blood flow; MPR, myocardial perfusion reserve; NS, not significant variables were eliminated in Stepwise analysis $(P>0.05)$. 
significantly with hypertension after adjusting for age and gender in multivariate analysis.

The mechanisms underlying microvascular dysfunction, leading to myocardial ischemia, in patients with hypertension without coronary artery disease is not yet clear. In patients with hypertension, rest MBF was adapted to not only the higher myocardial oxygen consumption ${ }^{25}$ but also increments in the tone of coronary resistance vessels due to higher blood pressure and extravascular compression in the presence of LV hypertrophy. ${ }^{23}$ Thus, structural changes in the coronary vasculature may be the major contributors to impaired MPR. Abnormalities in coronary reactivity may also exist in asymptomatic hypertensive individuals. ${ }^{2,26}$ Hypertension reduces endothelial responses with relaxation to acetylcholine, ADP and thrombin in large vessels, ${ }^{27,28}$ which reduces MPR.

Di Carli et al. demonstrated that the increase in ATP stress MBF was similar in subjects with type 1 and type $2 \mathrm{DM}$, but lower than in the controls group, although basal MBF was similar among these three groups. ${ }^{29}$ Inconsistent with the study, the present result shows that DM was not associated with MPR. The severity of DM in the present study (HbA1c $6.7 \pm 1.3 \mathrm{mg}$ per $100 \mathrm{ml}$ ) was less than that study (type 1 DM: $10.7 \pm 2.8 \mathrm{mg}$ per $100 \mathrm{ml}$ ), which may explain the discrepancy of the results. Pitkanen et al. demonstrated that coronary flow reserve was reduced in young men with familial hypercholesterolemia and consequently coronary resistance during hyperemia is increased. ${ }^{4}$ However, in the present study, dyslipidemia was not associated with MPR probably because of the difference in severity of the disease (mean total cholesterol levels: $298 \pm 73$ vs. $208.7 \pm 32 \mathrm{mg}$ per $100 \mathrm{ml}$ ).

\section{Limitations}

There are several limitations in this study. First, it should be pointed out that the present study is not a real epidemiological study. The participants were the patients who had undergone cardiac MRI in hospital. Second, exclusion of significant coronary artery disease was on the basis of the absence of regional heterogeneity of MBF on rest perfusion MRI. The influence of anti-hypertensive medication on MPR should be considered. In the present study, 65 in 84 hypertensive patients took medication for hypertension. No difference was found in MPR between the groups with and without calcium-channel blocker, or between those with and without beta-blocker. However, MPR in groups with angiotensin converting enzyme inhibitors or angiotensin receptor blocker was significantly lower than that without those medicines (Figure 3). It has been reported that angiotensin converting

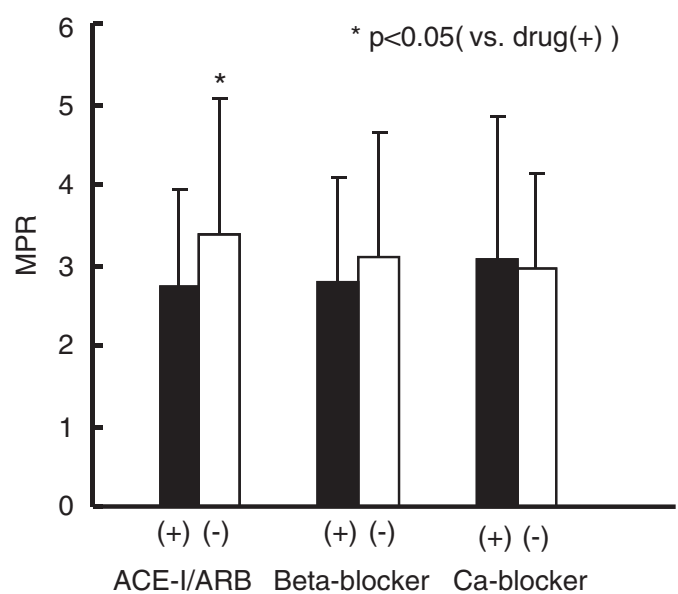

Figure 3 The effect of calcium-channel blocker (Ca-blocker), beta-blocker and angiotensin converting enzyme inhibitors (ACE-I) or angiotensin receptor blocker on MPR. enzyme inhibitors/angiotensin receptor blocker improved $\mathrm{MPR},{ }^{30}$ so that in the present study angiotensin converting enzyme inhibitors or angiotensin receptor blocker might be dispensed for patients with hypertension and impaired coronary micro-circulation.

\section{CONCLUSION}

We evaluated MPR in patients without myocardial ischemia using perfusion MR images. Hypertension was the most important effector of MPR and may be the most important factor for cardiovascular disease from the viewpoint of MPR in subjects without myocardial ischemia.

1 Camici PG, Crea F. Coronary microvascular dysfunction. N Engl J Med 2007; 356: 830-840.

2 Erdogan D, Yildirim I, Ciftci O, Ozer I, Caliskan M, Gullu H, Muderrisoglu H. Effects of normal blood pressure, prehypertension, and hypertension on coronary microvascular function. Circulation 2007; 115: 593-599.

3 Meyer C, Schwaiger M. Myocardial blood flow and glucose metabolism in diabetes mellitus. Am J Cardiol 1997; 80: 94A-101A.

4 Pitkanen OP, Raitakari OT, Niinikoski H, Nuutila P, lida H, Voipio-Pulkki LM, Harkonen $\mathrm{R}$, Wegelius $\mathrm{U}$, Ronnemaa T, Viikari J, Knuuti J. Coronary flow reserve is impaired in young men with familial hypercholesterolemia. J Am Coll Cardiol 1996; 28: 1705-1711.

5 Wang L, Jerosch-Herold M, Jacobs Jr DR, Shahar E, Folsom AR. Coronary risk factors and myocardial perfusion in asymptomatic adults: the Multi-Ethnic Study of Atherosclerosis (MESA). J Am Coll Cardiol 2006; 47: 565-572.

6 Kurita T, Sakuma H, Onishi K, Ishida M, Kitagawa K, Yamanaka T, Tanigawa T, Kitamura $\mathrm{T}$, Takeda K, Ito M. Regional myocardial perfusion reserve determined using myocardial perfusion magnetic resonance imaging showed a direct correlation with coronary flow velocity reserve by Doppler flow wire. Eur Heart J 2009; 30: 444-452.

7 Sakuma H, Suzawa N, Ichikawa Y, Makino K, Hirano T, Kitagawa K, Takeda K. Diagnostic accuracy of stress first-pass contrast-enhanced myocardial perfusion MRI compared with stress myocardial perfusion scintigraphy. Am J Roentgenol 2005; 185: 95-102.

8 Ichihara T, Ishida M, Kitagawa K, Ichikawa Y, Natsume T, Yamaki N, Maeda H, Takeda K, Sakuma H. Quantitative analysis of first-pass contrast-enhanced myocardial perfusion MRI using a Patlak plot method and blood saturation correction. Magn Reson Med 2009; 62: 373-383.

9 Costa MA, Shoemaker S, Futamatsu H, Klassen C, Angiolillo DJ, Nguyen M, Siuciak A, Gilmore P, Zenni MM, Guzman L, Bass TA, Wilke N. Quantitative magnetic resonance perfusion imaging detects anatomic and physiologic coronary artery disease as measured by coronary angiography and fractional flow reserve. J Am Coll Cardiol 2007; 50: 514-522.

10 Lee DC, Simonetti OP, Harris KR, Holly TA, Judd RM, Wu E, Klocke FJ. Magnetic resonance versus radionuclide pharmacological stress perfusion imaging for flowlimiting stenoses of varying severity. Circulation 2004; 110: 58-65.

11 Jerosch-Herold M, Wilke N, Stillman AE. Magnetic resonance quantification of the myocardial perfusion reserve with a Fermi function model for constrained deconvolution. Med Phys 1998; 25: 73-84.

12 Jerosch-Herold M, Swingen C, Seethamraju RT. Myocardial blood flow quantification with MRI by model-independent deconvolution. Med Phys 2002; 29: 886-897.

13 Diesbourg LD, Prato FS, Wisenberg G, Drost DJ, Marshall TP, Carroll SE, O'Neill B. Quantification of myocardial blood flow and extracellular volumes using a bolus injection of Gd-DTPA: kinetic modeling in canine ischemic disease. Magn Reson Med 1992; 23: 239-253.

14 Larsson HB, Fritz-Hansen T, Rostrup E, Sondergaard L, Ring P, Henriksen O. Myocardial perfusion modeling using MRI. Magn Reson Med 1996; 35: 716-726.

15 Vallee JP, Lazeyras F, Kasuboski L, Chatelain P, Howarth N, Righetti A, Didier D. Quantification of myocardial perfusion with FAST sequence and Gd bolus in patients with normal cardiac function. J Magn Reson Imaging 1999; 9: 197-203.

16 Hsu LY, Rhoads KL, Holly JE, Kellman P, Aletras AH, Arai AE. Quantitative myocardial perfusion analysis with a dual-bolus contrast-enhanced first-pass MRI technique in humans. J Magn Reson Imaging 2006; 23: 315-322.

17 Pilz G, Klos M, Ali E, Hoefling B, Scheck R, Bernhardt P. Angiographic correlations of patients with small vessel disease diagnosed by adenosine-stress cardiac magnetic resonance imaging. J Cardiovasc Magn Reson 2008; 10: 8 .

18 Vogt M, Motz W, Strauer BE. Coronary haemodynamics in hypertensive heart disease. Eur Heart J 1992; 13: 44-49.

19 Gimelli A, Schneider-Eicke J, Neglia D, Sambuceti G, Giorgetti A, Bigalli G, Parodi G, Pedrinelli $\mathrm{R}$, Parodi $\mathrm{O}$. Homogeneously reduced versus regionally impaired myocardial blood flow in hypertensive patients: two different patterns of myocardial perfusion associated with degree of hypertrophy. J Am Coll Cardiol 1998; 31: 366-373.

20 Luscher TF, Raij L, Vanhoutte PM. Endothelium-dependent vascular responses in normotensive and hypertensive Dahl rats. Hypertension 1987; 9: 157-163.

21 Wang L, Jerosch-Herold M, Jacobs Jr DR, Shahar E, Detrano R, Folsom AR, MESA Study Investigators. Coronary artery calcification and myocardial perfusion in asymptomatic adults: the MESA (Multi-Ethnic Study of Atherosclerosis). J Am Coll Cardiol 2006; 48: 1018-1026. 
22 Davis LE, Hohimer AR, Morton MJ. Myocardial blood flow and coronary reserve in chronically anemic fetal lambs. Am J Physiol 1999; 277: R306-R313.

23 Treasure CB, Klein JL, Vita JA, Manoukian SV, Renwick GH, Selwyn AP, Ganz P, Alexander RW. Hypertension and left ventricular hypertrophy are associated with impaired endothelium-mediated relaxation in human coronary resistance vessels. Circulation 1993; 87: 86-93.

24 Chade AR, Brosh D, Higano ST, Lennon RJ, Lerman LO, Lerman A. Mild renal insufficiency is associated with reduced coronary flow in patients with non-obstructive coronary artery disease. Kidney Int 2006; 69: 266-271.

25 Brilla CG, Janicki JS, Weber KT. Impaired diastolic function and coronary reserve in genetic hypertension. Role of interstitial fibrosis and medial thickening of intramyocardial coronary arteries. Circ Res 1991; 69: 107-115.

26 Takamura T, Onishi K, Sugimoto T, Kurita T, Fujimoto N, Dohi K, Tanigawa T, Isaka N, Nobori T, Ito M. Patients with a hypertensive response to exercise have impaired left ventricular diastolic function. Hypertens Res 2008; 31: 257-263.
27 Heller LI, Cates C, Popma J, Deckelbaum LI, Joye JD, Dahlberg ST, Villegas BJ, Arnold A, Kipperman R, Grinstead WC, Balcom S, Ma Y, Cleman M, Steingart RM, Leppo JA. Intracoronary Doppler assessment of moderate coronary artery disease: comparison with 201TI imaging and coronary angiography. FACTS Study Group. Circulation 1997; 96: 484-490.

28 Kozakova M, Palombo C, Pratali L, Pittella G, Galetta F, L'Abbate A. Mechanisms of coronary flow reserve impairment in human hypertension. An integrated approach by transthoracic and transesophageal echocardiography. Hypertension 1997; 29: 551-559.

29 Di Carli MF, Janisse J, Grunberger G, Ager J. Role of chronic hyperglycemia in the pathogenesis of coronary microvascular dysfunction in diabetes. J Am Coll Cardiol 2003; 41: 1387-1393.

30 Hinoi T, Tomohiro Y, Kajiwara S, Matsuo S, Fujimoto Y, Yamamoto S, Shichijo T, Ono T. Telmisartan, an angiotensin II type 1 receptor blocker, improves coronary microcirculation and insulin resistance among essential hypertensive patients without left ventricular hypertrophy. Hypertens Res 2008; 31: 615-622. 